\title{
Ten Years of Stochastic Water Supply Modeling by Lower Colorado River Authority of Texas
}

\author{
Ronald E. Anderson and J. David Walker
}

Lower Colorado River Authority, Austin, Texas.

\begin{abstract}
Following the drought of 2006 and 2007, the Lower Colorado River Authority (LCRA) developed a medium-range forecast model to incorporate stochastically generated hydrology. The model generates inflows and evaporation forecasts by Monte Carlo sam-pling from monthly historical records over $75 \mathrm{y}$. by applying Markov chain methods conforming to historical cumulative inflow frequencies. LCRA has used the model continuously since its development, including during the severe multi-year drought from 2008 to 2016, when it was used to forecast system storage and lake level outcomes. During this period, LCRA revised the model to reflect three different reservoir operating plans, changes in environmental flow requirements, and to incorporate newly available El Niño-Southern Oscillation (ENSO) forecasts and newer hydrologic records. LCRA used the water supply forecasts for contin-gency planning during the drought. There are many continuing users for lake level and storage forecasts: water treatment plant operators; recreational business owners, such as boat ramp and marina operators; water conservation managers; power plant operators; and downstream agricultural producers and irrigators. Each user has unique needs for drought response lead times and has different levels of risk aversion. In addition to forecasting and contingency planning, the stochastic model has been used to re-evaluate lake operating guidelines and management strategies originally developed using deterministic methods. The use of stochastic modeling introduced new planning and policy challenges, including identifying risk tolerances and determining the significance of drought events. Future model improvements may include adjustments for deep persistence low rainfall runoff and migration to a more detailed river system modeling platform.
\end{abstract}

\section{Background}

LCRA is a conservation and reclamation district created by the Texas Legislature in 1934. LCRA generates and transmits electric power, manages water supply and floods in the Lower Colorado River basin, provides public parks, and supports community and economic development. LCRA manages water supplies for cities, industries and agriculture along a 600 mile $(1000 \mathrm{~km})$ stretch of the Colorado River in Texas between San Saba and the Texas Gulf Coast. LCRA's water supply includes a combination of firm water supply for municipal and industrial uses, and interruptible water supply for agricultural uses.

LCRA operates six dams on the lower Colorado River in Central Texas: Buchanan, Inks, Wirtz, Starcke, Mansfield and Tom Miller. These dams form the six Highland Lakes-Buchanan, Inks, LBJ, Marble Falls, Travis and Austin-as shown schematically in Figure 1. Two of these reservoirs, Lake Buchanan and Lake Travis, are water supply reservoirs, and only Lake Travis has the ability to hold floodwaters. The total combined storage of Lake Buchanan and Lake Travis is 2 010000 acre-feet (248 000 ha m) water when at full conservation storage. LCRA regulates water discharges to manage floods, and releases water for sale to municipal, agricultural and industrial users. Hydroelectric plants at the dams provide $\sim 295 \mathrm{MW} / \mathrm{y}$ electricity.

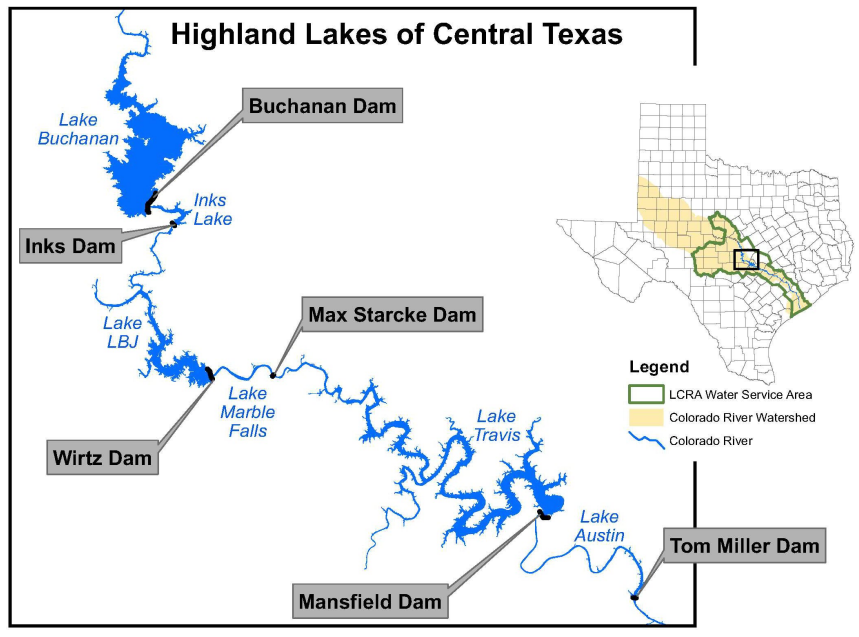

Figure 1 The Highland Lakes chain along the Colorado River in Texas.

Predicting streamflows in the Lower Colorado River basin can better inform resource planning and management for water

Anderson, Ronald E. and J. David Walker. 2017. Ten Years of Stochastic Water Supply Modeling by Lower Colorado River Authority of Texas. Journal of Water Management Modeling 26:C432. https://doi.org/10.14796/JWMM.C432

(c) CHI 2017. www.chijournal.org ISSN 2292-6062. 
supply, physical facilities, flood management, hydroelectric generation and scheduling, and environmental provisions.

There are many factors that make long lead time streamflow prediction difficult in Central Texas. The lack of snow pack precludes one of the most helpful predictions available to our counterparts in states in the Southwest, Pacific Northwest and Atlantic Northeast. Additionally, Central Texas weather patterns are influenced by Pacific, Arctic and Canadian fronts, the Atlantic Ocean, the Gulf of Mexico, and tropical disturbances (Nielsen-Gammon 2011). Stalled fronts can occasionally be the focus of large rain storms, as during the Memorial Day flood of 1981.

\section{Review of Hydrological Models}

LCRA first began to research uncertainty methods following the severe drought of 1983-1984, during which LCRA experienced rapid and dramatic reductions of water in conservation storage. LCRA sponsored research that was published as "Projecting Storage in the Highland Lake Reservoir System" (Vaugh and Maidment 1987). This work laid out statistical approaches and applications to the Highland Lakes and recommended future areas of research. It also illustrated the application of the tools to the Highland Lakes using historical annual sequences sampled from 41 years of data. The research showed that the LCRA water supply system reaches a stochastic equilibrium after only a few years of simulation.

Subsequently, the State of Texas investigated similar methods, and Alfredo Rodriguez published a master's thesis on probability methods for reservoir management in Texas reservoirs (Rodriguez 1993). Although not specifically applied to the lower Colorado River, Rodriguez's work serves as a case study.

Following the 2000 drought, LCRA funded further research into stochastic methods. The work was published as "Stochastic Optimization of the Highland Lakes System in Texas" (Kracman et al. 2006) and "Stochastic Reservoir System Analysis" (O'Connell 2002). The model developed from these combined efforts used parametric statistics with a branched logic approach to reduce the problem size for ease of computation. Formulated as an optimization model, the model still required advanced solvers to execute (Watkins et al. 2000). Cornell University, in partnership with the Palisade Corporation and LCRA, published "A Sampling-Based Stochastic Programming Approach to Water Resources Management" which applied to the Lower Colorado River (Bhadauria et al. 2005).

Following another severe drought in 2006, LCRA pursued additional stochastic modeling with Hydrosphere Resource Consultants (HRC, now Hydros Consulting Inc.). This work benefited from lessons learned from prior efforts, particularly the difficulties of applying parametric statistics to spatially distributed inflow systems as identified by Kracman and by O'Connell. This effort applied non-parametric methods to synthetic inflow set generation and used the RiverWare software from the Center for Advanced Decision Support for Water and Environmental Sys-tems (CADSWES) at the University of Colorado as the simulation platform (HRC 2007). Unfortunately, the model relied on an older computational method, which required long execution times-an issue CADSWES has since overcome. HRC generated synthetic hydrology sets by sampling 100 series, limited due to execution time, from $58 \mathrm{y}$ of historical annual sequences, which resulted in a coarse sample of outcomes. At about the same time, Whiting (2006) was exploring the concept of persistence flow projections on other watersheds with Markov models. LCRA's current stochas-tic model builds on these prior efforts.

\section{Model Development and Updates}

Following the droughts in 2006 and 2007, LCRA developed a medium range forecast model to incorporate stochastically generated hydrology. LCRA has used the model continually since its development, including during the severe multi-year drought from 2008 to 2016 when it was used to forecast system storage and lake level outcomes. During this period, LCRA revised the model to reflect three different reservoir operating plans, changing environmental flow requirements, and to incorporate newly available El Niño-Southern Oscillation (ENSO) forecasts and newer hydrologic records. ENSO has been shown to influence precipitation and streamflow in Central Texas (Gershunov 1998; Rajagopalan and Cooke 2000; Watkins and O'Connell 2005; Slade and Chow 2011; Vicente-Serrano et al. 2011; Wei and Watkins 2011; Anderson and Rose 2012). The ability to predict ENSO has been improving with statistical and dynamic models (Quan et al. 2006; Barnston et al. 2012; Tippett et al. 2012). A more in-depth discussion of the model's use of ENSO ensemble forecasts can be found in Anderson et al. (2015).

LCRA developed its model in time to inform management during the significant drought conditions in 2008 and 2009. Substantial drought relief came in 2010. Then in 2011, La Niña conditions contributed to lower-than-average precipitation in Central Texas. In early spring 2011, an intense high pressure ridge formed over the south central United States, keeping rain and storms away from most of the state. A flash drought developed because of the unprecedented dry and hot weather conditions. During the summer of 2011, Central Texas also experienced brutal heat with $\sim 90 \mathrm{~d}$ having temperatures $\geq 100^{\circ} \mathrm{F}\left(38^{\circ} \mathrm{C}\right)$. In 2011, inflows into the Highland Lakes were the lowest on record. The model's ability to show that the unprecedented duration of low inflows was within the range of possible flows and in the lower tail of the distribution gave confidence in the model's validity. In-flows increased somewhat in 2012. But in 2013 and 2014, record low inflows also occurred. In 2016, the Highland Lakes were at full conservation storage again. The drought from 2008 to 2016 is by many measures the most severe drought on record for the Central Texas region. During the course of the drought, the model was reviewed by state agencies and stakeholders, resulting in the institutionalization of the model.

The historic drought was a difficult period for water supply management and operations, and could have been extremely challenging for concurrent water supply model development, adoption, acceptance and utility. However, the LCRA experience was that model adoption, review and use was driven by a compelling need for current information. Figure 2 chronicles modeling development and updates during the many fluctua- 
tions in water supply storage as well as the major milestones for LCRA's water management plan. From 2006 to 2017, LCRA oper-ated under three different water management plans, and under a series of emergency orders in 2012-2015 that cut off water for three irrigation operations which LCRA serves.

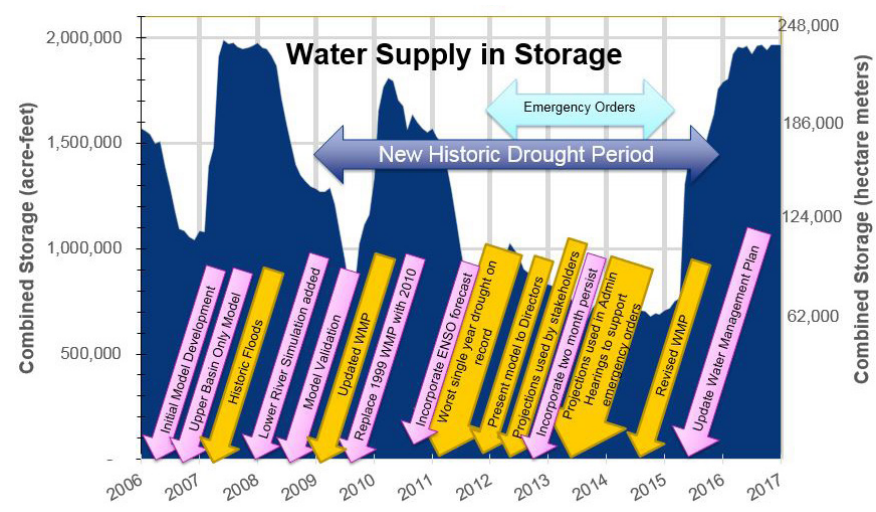

Figure 2 Model and drought timeline.

\section{Model Methods}

\subsection{Model Inputs}

\section{Hydrologic and Climatological Data Sets}

Historical hydrology: The model currently uses the hydrological record from 1940 to 2015, including upstream inflows, downstream run-of-river flows, and evaporation records for every month of the period. The period includes the $10 \mathrm{y}$ drought of the $1950 \mathrm{~s}$, the state's drought of record, and the drought of 2011, which is the most severe $1 \mathrm{y}$ drought on record. The dataset is updated each year as more data becomes available. The historical inflows determine the month-to-month transitional probabilities required by the Markov chain technique.

Firm customer demands: The model uses firm customer base demands based on recent experience. Drought year demands may be used when evaluating the impacts of drought on the water supply because drought conditions increase the demand for stored water that is otherwise met through rainfall.

Interruptible customer requests: The model uses the anticipated planted acreage served by LCRA's four irrigation operations to determine how much water the downstream interruptible customers would require if all agricultural irrigation demands are to be satisfied.

\section{Operational Inputs}

Water management plan currently in effect: LCRA manages Lake Travis and Lake Buchanan under a state-approved water management plan. The plan governs LCRA's operation of the Highland Lakes to supply water to users throughout the Lower Colorado River basin.

During drought, the plan requires that interruptible stored water from the Highland Lakes be restricted or cut off for downstream agriculture so that firm water supplies will be available for the basic needs of cities, businesses and industries. The plan also requires LCRA to provide water from the lakes to help meet the environmental needs of the Lower Colorado River and Matagorda Bay.

The Texas Commission on Environmental Quality approved the current plan in November 2015. The 2015 water management plan allows LCRA to quickly adapt its operations as water supply conditions change. The plan established three sets of operating conditions to determine the availability of interruptible stored water, which is primarily used by agricultural customers in Colorado, Wharton and Matagorda counties. It also set two datesMarch 1 and July 1 -for determining the amount of interruptible stored water available for first and second crops.

\section{Current System Status and Short Term ENSO Forecasts}

Reservoir storage: Each month, when the projections are updated, the current levels of Lake Travis and Lake Buchanan serve as the model's starting point.

A measurement of the El Niño-Southern Oscillation index: ENSO is a cyclic warming and cooling of sea surface temperatures in the Pacific Ocean near the equator which can affect weather patterns across the United States. If the Pacific warms sufficient-ly, it can produce an El Niño that increases the probability of wetter-thannormal weather in Central Texas, particularly during the fall and winter. If the Pacific is cool enough, it can produce a La Niña that increases the probability of dry weather in Central Texas. The El Niño-Southern Oscillation index (ONI, oceanic Niño index) is a measure of this cycle. LCRA uses ONI in its model to help predict whether future conditions should be weighted toward a wet, dry, or neutral scenario. Current conditions and future ensembles of the index are provided by the International Research Institute for Climate and Society of Columbia University and by the Climate Prediction Center (CPC) of the National Weath-er Service (IRI 2017). The index is updated monthly. A recent sample is shown in Figure 3.

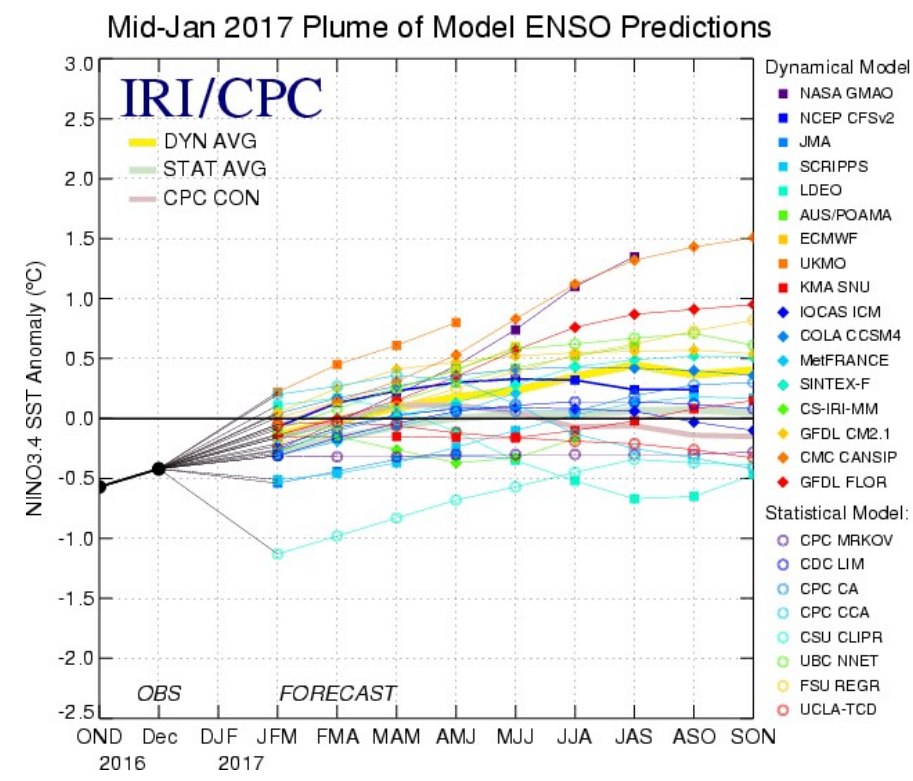

Figure 3 IRI ENSO forecast. 
The ensemble of ENSO forecasts cannot be directly incorporated into LCRA's stochastic model framework. However, the ENSO forecasts are classified into El Niño, Neutral or La Niña states. An El Niño state is characterized by a positive $\mathrm{ONI} \geq+0.5^{\circ} \mathrm{C}$ while a La Niña state is characterized by a negative $\mathrm{ONI} \leq-0.5^{\circ} \mathrm{C}$. Anything in between is neutral. It is important to make a distinction between a state and a condition. In order for CPC to declare a condition of El Niño or La Niña, the monthly El Niño sea surface temperature departures must meet or exceed $\pm 0.5^{\circ} \mathrm{C}$ on average for three consecutive months, and the atmosphere must display characteristics consistent with the defined conditions.

Transitional probabilities of changing from one state to another in any month can be computed from the ensemble of projections. The table of transition state probabilities is readily incorporated into a non-parametric Monte Carlo methodology of generating 2000 equally likely stochastic future streamflow scenarios in much the same manner as streamflow transitions already incorporated into the model (Anderson and Rose 2012).

Last two months of inflows: The model uses historical inflow data for the last $75 \mathrm{y}$ to help evaluate the likelihood of possible future conditions. The model specifically uses inflow data from the last two months to help determine one very important factor: the probability that the region's weather pattern could change significantly from one month to the next.

Historical data shows the tendency for the weather to stay the same from one month to the next in Texas, particularly during the winter months and to a lesser extent in May through October. If the weather is wet one month, it tends to stay wet the next month. Conversely, if it is dry one month, it tends to stay dry the next. This is the norm, but it does not always hold true. The weather does change eventually.

Through years of improving the model, LCRA found the best way to evaluate the likelihood of a significant change in the weather is to use the most recent two months of inflows to determine if there is a wet, dry or neutral weather pattern; and to look at the historical record to determine how often the weather pattern has changed from one month to the next. The model can use this data to determine the probability that the local weather will change significantly from one month to the next (e.g. from wet to dry, dry to wet, neutral to dry, and so on).

\subsection{Model Methods}

The model gives a month-by-month re-ordering of the historical hydrology according to a rational method that preserves the historical observed switching patterns (wet, neutral, dry) and preserves the cumulative historical frequency of inflows to the Highland Lakes. This is the stochastic part of the model. Then the model simulates the operation of the system to meet demands and determines the monthly lake storage. This is the accounting part of the model. The model does this 2000 times.

The model extent is primarily the inflows into and releases from the Highland Lakes but also includes the reliable downstream river flows due primarily to discharges from Austin. Lake
Buchanan, Lake Travis and Matagorda Bay are the only points of monthly mass balance accounting.

The entire model operates in Microsoft Excel. The historical inflow from 1940 to 2015 is sampled using a Monte Carlo informal Markov chain process to produce 2000 hydrologic inflow sets each of 60 months in duration. The historical flows have been adjusted to account for the construction of a major upstream reservoir in 1990. The Monte Carlo process allows re-sampling observations. The large number of inflow sets provides a sampling of future outcomes with 20 forecasts falling below $1 \%$ likelihood. Sampling is conditioned based on the past month's inflows and historically observed month-to-month transitional probability in order to reproduce the posterior distributions of annual and multi-year inflow frequencies consistent with the hydrologic record.

The mechanism for shaping the stochastically generated inflows to conform to the posterior distribution is by selection from the inflow condition with the same frequency and the month-to-month transitional persistence frequency. (Anderson and Walker 2011). For this model the frequencies of transition from dry quartile, inner quartile range (moderate), and wet quartile were computed from historical occurrence for the gauged record of 1940-2015.

\subsection{Model Outputs}

Through the course of the modeling period, LCRA has required and used multiple model outputs. During the drought very detailed outputs were of interest. The standard way of presenting the results has been fairly stable. The projections illustrate the likelihood of future combined storage content in Lake Travis and Lake Buchanan for 25\%, 50\%, 90\% and 99\% exceedance, shown by green, blue, dark red and bright red lines respectively in Figure 4. This is only one of several ways to summarize and view the storage and lake level forecasts. Based on these forecasts, water conservation managers had $>9$ month lead time to prepare conservation communications and action plans, if needed.

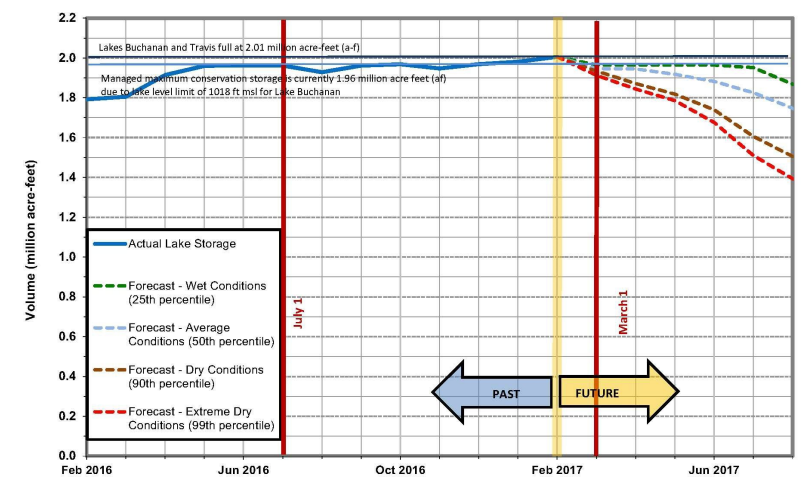

Figure 4 Lake Travis and Lake Buchanan combined storage.

An alternate view of the output is the long term forecast as shown in Figure 5. This view has an advantage over the forecast shown in Figure 3, in that it does not overemphasise the lines of equal likelihood, which a casual observer might misinterpret 
as projected storage traces. Instead it focuses on the regions of likelihood.

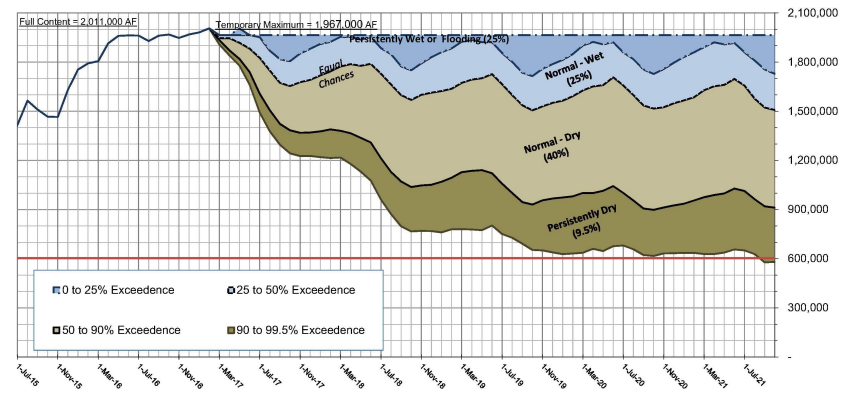

Figure 5 Combined storage forecast.

Finally, cities which have intakes on the lakes are more concerned about individual lake forecasts than they are about the total water supply inventory. Therefore, reports also include future lake level probabilities for Lake Travis and Lake Buchanan. An example of the recent Lake Travis level forecast is shown in Figure 6.

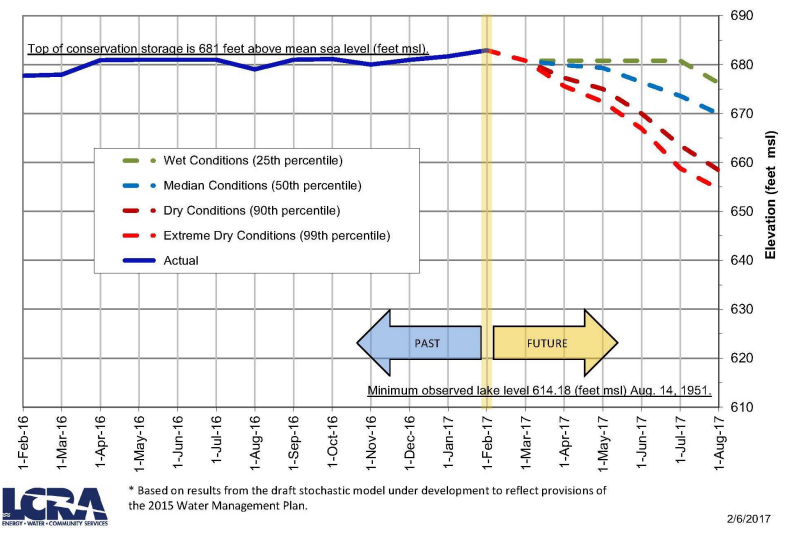

Figure 6 Lake Travis level forecast.

\section{Observations}

Concurrent extreme hydrologic conditions helped LCRA develop, adopt and use stochastic modeling for looking at possible future water supply storage. It was reassuring that the model captured the extreme conditions that were experienced during the drought. The ease with which the latest hydrology and climatology can be added to the model to keep it up-to-date is a key advantage of the approach. This was particularly important when the region was experiencing new hydrologic extremes. Modifying the model in a spreadsheet made it reasonably simple to change model simulations of operations under multiple management plans and emergency orders. Finally, the use of non-parametric statistics results in some limitations but it helped stakeholders and regulators initially accept the model and model methods. The model is in continual use and the monthly updates can be found at https://hydromet.lcra.org/riverreport/.

\section{References}

Anderson, R. E. and B. Rose. 2012. "Searching for Predictive Climate Signals for River Flows in the Lower Colorado River Basin of Texas." In Irrigated Agriculture Responds to Water Use Challengers-Strategies for Success, Austin, TX April 3-6, 2012, 63-74. Denver, CO: USCID (U.S. Committee on Irrigation and Drainage).

https://dspace.library.colostate.edu/bitstream/handle/10217/79326/107_2012_TX_USCID_Anderson.pdf?sequence $=7 \&$ isAllowed $=\mathrm{y}$

Anderson, R. E., B. Rose and L. Oliver. 2015. “Use of IRI Ensembles to Characterize ENSO Uncertainty in Water Supply Forecasting for the Lower Colorado River in Texas." In ASCE EWRI Watershed Management Symposium, 2015. Reston, VA: ASCE. https://doi.org/10.1061/9780784479322.008

Anderson, R. E. and D. Walker. 2011. “Use of Stochastic Modeling during the 2008 and 2009 Drought on the Lower Colorado River in Texas." ASCE/EWRI Water Resources World Congress, Palm Springs, California. Reston, VA: ASCE. https://doi.org/10.1061/41173(414)325

Barnston, A. G., M. K. Tippett, M. L. L'Heureux, S. Li and D. G. DeWitt. 2012."Skill of Real-Time Seasonal ENSO Model Predictions during 2002-11: Is Our Capability Increasing?" Bulletin of the American Meteorological Society 93:631-51. https://doi.org/10.1175/BAMS-D-11-00111.1

Bhadauria G., R. C. de Beauregard and A. Pollock. 2005. A Sampling Based Stochastic Programming Approach to Water Resources Management. Ithaca, NY: Cornell University. Master of Engineering project report (Operations Research).

Gershunov, A. 1998. “ENSO Influence on Intraseasonal Extreme Rainfall and Temperature Frequencies in the Contiguous United States: Implications for Long-Range Predictability." American Meteorological Society Journal of Climate 11:3192-203.

HRC (Hydrosphere Resource Consultants). 2007. Lower Colorado River Authority Water Supply Reliability Study, Final Report.

IRI (International Research Institute for Climate and Society). 2017. IRI ENSO Forecast. Palisades, NY: Earth Institute, Columbia University.

http://iri.columbia.edu/our-expertise/climate/forecasts/ enso/current/

Kracman, D. R., D. C. McKinney, D. W. Watkins Jr and L. S. Lasdon. 2006. "Stochastic Optimization of the Highland Lakes System in Texas." Journal of Water Resources Planning and Management 132 (2). https://doi.org/10.1061/(ASCE)0733-9496(2006)132:2(62)

Nielsen-Gammon, J. W. 2011. “Long-Term Trends in Southern Plains Drought." Presented at Managing Drought in the Southern Plains, Southern Climate Impacts Planning Program, ENSO, PDO, AMO and alphabet soup, presentation on October 13, 2011. 
O'Connell, S. M. 2002. The Use of Predictive Climate Signals in Synthetic Streamflow Development for Central Texas Water Management. Houghton, MI: Michigan Technological University. Master's thesis.

Quan, X., M. Hoerling, W. Bates and T. Xu. 2006. "Diagnosing Sources of U.S. Seasonal Forecast Skill." American Meteorological Society Journal of Climate 19:3279-93.

Rajagopalan, B. and E. Cooke. 2000. “Spatiotemporal Variability of ENSO and SST Teleconnections to Summer Drought over the United States During the Twentieth Century." American Meteorological Society Journal of Climate 13:4244-55.

Rodriguez, D. A. 1993. The Use of Conditional Probability Analysis as a Management Technique for Reservoirs in the State of Texas. Austin, TX: The University of Texas at Austin. Master's thesis.

Slade, R. M and T. E. Chow. 2011. "Statistical Relations of Precipitation and Stream Runoff for El Niño and La Niña Periods, Texas Hill Country." Texas Water Journal 2 (1): 1-22.

Tippett, M. K., A. G. Barnston and S. Li. 2012. “Performance of Recent Multimodel ENSO Forecasts." Journal of Applied Meteorology and Climatology 51 (3): 637-54. https://doi.org/10.1175/JAMC-D-11-093.1

Vaugh, S. K. and D. R. Maidment. 1987. "Projecting Storage in Highland Lake Reservoir System." Journal of Water Resource Planning and Management 113 (5): 659-76.
Vicente-Serrano, S. M., J. I. López-Moreno, L. Gimeno, R. Nieto, E. Morán-Tejeda, J. Lorenzo-Lacruz, S. Beguería and C. Azorin-Molina. 2011. "A Multiscalar Global Evaluation of the Impact of ENSO on Droughts." Journal of Geophysical Research 116:D20109. https://doi.org/10.1029/2011JD016039

Watkins Jr, D. W., D. C. McKinney, L. S. Lasdon, S. S. Nielsen and Q. W. Martin. 2000. "A Scenario-Based Stochastic Programming Model for Water Supplies from the Highland Lakes." International Transactions in Operational Research 7 (3): 211-30. https://doi.org/10.1016/S0969-6016(99)00021-0

Watkins Jr, D. W. and S. M. O'Connell. 2005. “Teleconnections and Disconnections in Central Texas: A Guide for Water Managers. In Climate Variations, Climate Change and Water Resources Engineering, edited by J. Garbrecht and T. Piechota, 103-14. Reston, VA: ASCE Press.

Wei, W. and D. W. Watkins Jr. 2011. "Probabilistic Streamflow Forecasts Based on Hydrologic Persistence and Large-Scale Climate Signals in Central Texas." Journal of Hydroinformatics 13 (4): 760-74.

Whiting, J. P. 2006. Identification and Modeling of Hydrological Persistence with Hidden Markov Models. Adelaide: University of Adelaide. PhD dissertation. 